\title{
Strong tidal variations in ice flow observed across the entire Ronne Ice Shelf and adjoining ice streams
}

\author{
Sebastian H. R. Rosier ${ }^{1}$, G. Hilmar Gudmundsson ${ }^{1}$, Matt A. King ${ }^{2}$, Keith W. Nicholls ${ }^{1}$, \\ Keith Makinson $^{1}$, and Hugh F. J. Corr ${ }^{1}$ \\ ${ }^{1}$ British Antarctic Survey, High Cross, Madingley Road, Cambridge, UK \\ ${ }^{2}$ University of Tasmania, Hobart, Tasmania, Australia \\ Correspondence to: Sebastian H. R. Rosier (s.rosier@ bas.ac.uk)
}

Received: 7 July 2017 - Discussion started: 17 July 2017

Revised: 28 September 2017 - Accepted: 5 October 2017 - Published: 20 November 2017

\begin{abstract}
We present a compilation of GPS time series, including those for previously unpublished sites, showing that flow across the entire Ronne Ice Shelf and its adjoining ice streams is strongly affected by ocean tides. Previous observations have shown strong horizontal diurnal and semidiurnal motion of the ice shelf, and surface flow speeds of Rutford Ice Stream (RIS) are known to vary with a fortnightly $\left(M_{\mathrm{sf}}\right)$ periodicity. Our new data set shows that the $M_{\mathrm{sf}}$ flow modulation, first observed on RIS, is also found on Evans, Talutis, Institute, and Foundation ice streams, i.e. on all ice streams for which data are available. The amplitude of the $M_{\text {sf }}$ signal increases downstream of grounding lines, reaching up to $20 \%$ of mean flow speeds where ice streams feed into the main ice shelf. Upstream of ice stream grounding lines, decay length scales are relatively uniform for all ice streams but the speed at which the $M_{\mathrm{sf}}$ signal propagates upstream shows more variation. Observations and modelling of tidal variations in ice flow can help constrain crucial parameters that determine the rate and extent of potential ice mass loss from Antarctica. Given that the $M_{\mathrm{sf}}$ modulation in ice flow is readily observed across the entire region at distances of up to $80 \mathrm{~km}$ upstream of grounding lines, but is not completely reproduced in any existing numerical model, this new data set suggests a pressing need to identify the missing processes responsible for its generation and propagation. The new GPS data set is publicly available through the UK Polar Data Centre at http://doi.org/10.5285/4fe11286-0e53-4a03-854c-a79a44d1e356.
\end{abstract}

\section{Introduction}

Ocean tides affect the flow of ice shelves (Doake et al., 2002; Legresy et al., 2004; Brunt et al., 2010; King et al., 2011a; Makinson et al., 2012) and ice streams (Anandakrishnan and Alley, 1997; Bindschadler et al., 2003b, a; Anandakrishnan et al., 2003; Gudmundsson, 2006; Marsh et al., 2013), often far upstream of their grounding lines (GLs). The growing availability of high temporal resolution data, particularly using GPS, has made the extent of these tidal effects increasingly apparent.

The Weddell Sea region is an ideal place to look for tidal effects on ice flow as it is subjected to the largest tides in Antarctica, with a tidal range of $\sim 7 \mathrm{~m}$ at the GLs of ice streams along the Zumberge Coast (Padman et al., 2002). The semidiurnal $M_{2}$ (principal lunar) and $S_{2}$ (principal solar) tides dominate the vertical tidal signal beneath most of the ice shelf and are characterized by an amphidromic point at the Ronne Ice Shelf calving front (Fig. 1a; Padman et al., 2002). An amphidromic point (or tidal node) is a point at which a tidal constituent has zero amplitude, around which that constituent rotates. The diurnal tides are smaller in amplitude, with no amphidromes in the region of interest and the phase propagating from east to west (Fig. 1b). These large and spatially variable tides have been observed to cause large temporal variations in the ice flow of this region, which in turn provides a unique opportunity to gain insights into ice-flow processes.

On the Whillans Ice Stream in the Ross Sea region, observations of stick-slip behaviour, modulated by the ocean tides (Bindschadler et al., 2003b, a), have proved invaluable 

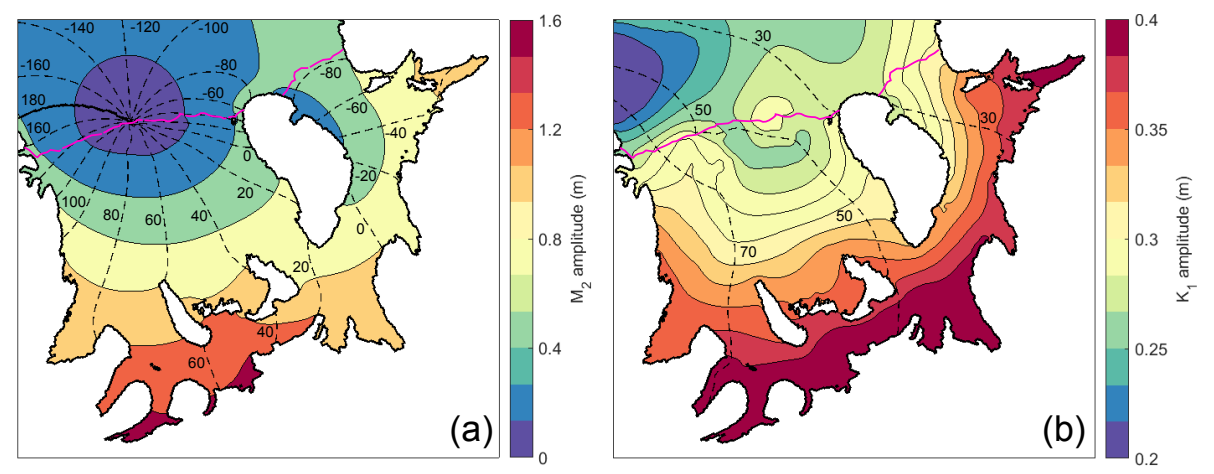

Figure 1. Amplitudes of the vertical semidiurnal $M_{2}$ (a) and diurnal $K_{1}$ (b) tides in the Weddell Sea region. Dashed lines are $20^{\circ}$ phase lines (also labelled in degrees), with the $M_{2}$ amphidromic point visible as the minimum in amplitude in (a). Solid magenta line shows the seaward extent of the FRIS. Note the difference in colour scale between the two panels. Amplitudes and phases are taken from the circum-Antarctic inverse model (CATS2008a, which is an updated version of the inverse tide model described by Padman et al., 2002).

to our understanding of the dynamics of its flow (Winberry et al., 2011, 2009; Sergienko et al., 2009; Winberry et al., 2014; Walker et al., 2016). Nearby, the flow of Bindschadler Ice Stream responds differently, exhibiting smooth diurnal velocity fluctuations in response to the mainly diurnal vertical tides (Anandakrishnan et al., 2003). On the FilchnerRonne Ice Shelf (FRIS) semidiurnal tidal motions have been observed to reach up to $\pm 300 \%$ of the mean flow (Makinson et al., 2012) and modulation of the flow of Ross Ice Shelf front is almost as large (Brunt et al., 2010). Attempts to produce models that can replicate these observations on ice shelves have had mixed results (Makinson et al., 2012; Brunt and MacAyeal, 2014).

A very different type of behaviour has been observed on Rutford Ice Stream (RIS), with fortnightly (2-weekly, $M_{\mathrm{sf}}$ ) variations in horizontal ice velocity of up to $20 \%$ of the mean flow (Gudmundsson, 2006). This observation is doubly interesting, in that it travels far upstream from the GL and the fortnightly period of the response is largely absent in the vertical tide that forces it. It also poses a potential aliasing issue when interpreting InSAR velocities based on image pairs separated by only a few days (Gudmundsson, 2006). Observations of fortnightly variations in ice flow have, until now, been limited to the Rutford Ice Stream (Gudmundsson, 2006), Larsen C Ice Shelf (King et al., 2011a) and Brunt Ice Shelf (G. H. Gudmundsson et al., 2017). Given the large semidiurnal tides across most of the Weddell Sea region it has been suggested that all large ice streams in this region will exhibit a behaviour similar to the RIS (Gudmundsson, 2007).

A number of mechanisms have been proposed to generate the nonlinearity which leads to this fortnightly signal, including a nonlinear basal sliding law (Gudmundsson, 2007, 2011; Rosier et al., 2014b), subglacial hydrology (Thompson et al., 2014; Rosier et al., 2015), asymmetric GL migration (Rosier et al., 2014b; Robel et al., 2017), and margin widening (Minchew et al., 2016). All of these mechanisms can generate an $M_{\mathrm{sf}}$ modulation in ice flow and may have validity for certain regions. However, a unified model is yet to reproduce all aspects of the observed behaviour. This has been highlighted by various recent observations, including the presence of an $M_{\mathrm{sf}}$ signal on ice shelves that are not fed by large ice streams (King et al., 2011a; G. H. Gudmundsson et al., 2017), and amplification of the RIS signal downstream of the GL (Minchew et al., 2016)

Here, we present a compilation of GPS data, including previously unpublished data on Evans (EIS), Talutis (TIS), and Foundation (FIS) ice streams and Carlson Inlet. In total, we include data from 28 new GPS sites, in addition to a new analysis of 15 previously published sites, and demonstrate for the first time the pervasive nature of these nonlinear tidal effects, easily observable across the entire region both on the ice shelf and upstream of ice stream GLs.

\section{Observations and data analysis}

A systematic campaign of GPS receiver deployments, designed to look for tidal modulation in ice flow, has been ongoing across the FRIS for a number of years. Some data have been published both for the main body of the floating ice shelf and the Rutford Ice Stream, but not for the remaining ice streams feeding into the ice shelf. The locations of all GPS receivers included in this compilation are shown in Fig. 2 and Table A1 summarizes key information for each site. GPS stations were powered with batteries charged by solar panels, and in some cases wind turbines to allow for continuous data collection over the winter.

All tidal constituents discussed in the text are listed in Table 1 with their respective periods. For an approximate indication of their relative importance in the vertical tides of this region we include a normalized amplitude, taken from the site FR05 time series, which is approximately central to the GPS sites presented here. This shows that, in terms of the vertical tides, the principal semidiurnal and diurnal constituents 


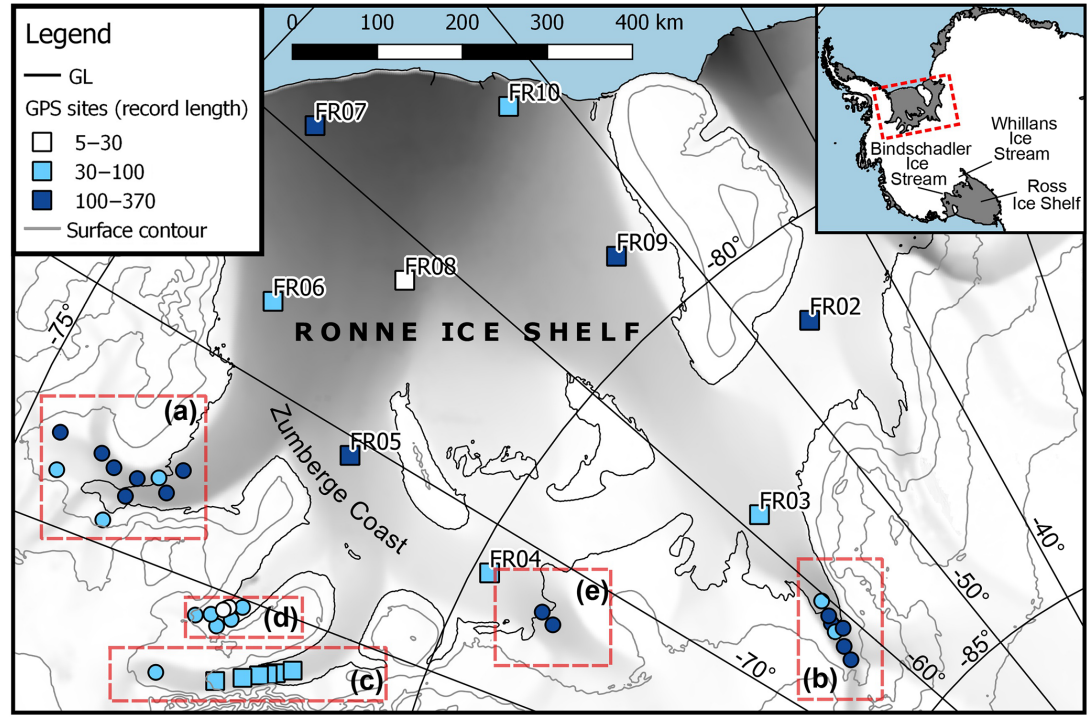

Figure 2. Map of the Filchner-Ronne Ice Shelf and adjoining ice streams. Circular markers show the location of new GPS sites included in this study and square markers are previously published sites. Marker colour indicates the approximate record length in days. The background colour scale shows ice speed from 0 to $2000 \mathrm{~m} \mathrm{a}^{-1}$ (white to black); grey lines are ice surface contours at $400 \mathrm{~m}$ intervals and black lines are grounding lines. Dashed red boxes mark the extent of panels for Evans Ice Stream (a), Foundation Ice Stream (b), Rutford Ice Stream (c), Talutis Ice Stream and Carlson Inlet (d), and Institute Ice Stream (e), which are also shown in Fig 3. Ice speed is from the MEaSUREs data set (Rignot et al., 2011), smoothed with a $1 \mathrm{~km}$ low-pass boxcar filter.

Table 1. Tidal constituents discussed in the text with their respective periods in days. Normalized amplitude is the vertical amplitude of each constituent at site FR05 as measured by GPS, normalized by the largest constituent $\left(M_{2}\right)$. Constituents marked with "_" were not considered significant by the tidal analysis and so their amplitudes are not shown.

\begin{tabular}{lrr}
\hline $\begin{array}{l}\text { Constituent } \\
\text { name }\end{array}$ & $\begin{array}{r}\text { Period } \\
\text { (days) }\end{array}$ & $\begin{array}{r}\text { Normalized vertical } \\
\text { amplitude }(\mathrm{m})\end{array}$ \\
\hline$M_{2}$ & 0.5175 & 1.000 \\
$S_{2}$ & 0.5000 & 0.645 \\
$O_{1}$ & 1.0758 & 0.397 \\
$K_{1}$ & 0.9973 & 0.395 \\
$M_{\mathrm{f}}$ & 13.6608 & 0.037 \\
$S_{\mathrm{sa}}$ & 182.6282 & 0.029 \\
$M_{\mathrm{sf}}$ & 14.7653 & - \\
\hline
\end{tabular}

are most important whereas long-period constituents, most notably the $M_{\text {sf }}$, are almost completely absent. Although the vertical tide has a spring-neap cycle which has the same fortnightly periodicity as the $M_{\mathrm{sf}}$, this is a wave envelope resulting from superposition of the two semidiurnal constituents and so does not contain any tidal energy at the $M_{\text {sf }}$ frequency (strictly speaking there is a weak astronomical forcing at the $M_{\text {sf }}$ frequency but it is not statistically significant in our vertical GPS data).

For the results and discussion that follow we will typically refer to ice displacements, rather than velocities. The main reason for this is that displacements are the direct result of GPS measurements, whereas velocities require taking derivatives of these observations potentially leading to noisy results (due to data errors) that require careful filtering.

GPS observations were made at a total of 43 sites using dual frequency GPS receivers placed on the ice surface. Processing of the nine previously published FR sites (all sites whose names begin with FR) was not redone and is described by King et al. (2011b) and King (2011). For all remaining sites the GPS data were processed using the kinematic precise-point positioning capabilities of the Bernese GNSS processing software, as described by Dach et al. (2009).

Our Bernese PPP analysis sub-samples the raw data to $30 \mathrm{~s}$ intervals and produces a three-dimensional position time series, with a correction for the solid earth tides. For the FR sites, additional corrections were made for the inverse barometer effect and ocean tide loading, as described by King et al. (2011b) and King (2011). For all other sites these corrections were not done since, in terms of the horizontal tidal motion to which we restrict our analysis, their effects are negligible. The processed results were subsequently downsampled using cubic interpolation and the $X$ and $Y$ positions then analysed to $5 \mathrm{~min}$ intervals. The number of useful days for each site, as shown in Table A1, is defined here as days with at least $95 \%$ data coverage.

Tidal analysis was done for every site using the "Unified Tidal analysis and prediction" MATLAB ${ }^{\circledR}$ software, referred to henceforth as UTide (Codiga, 2011). UTide uses an iteratively reweighted least squares (IRLS) solution method 


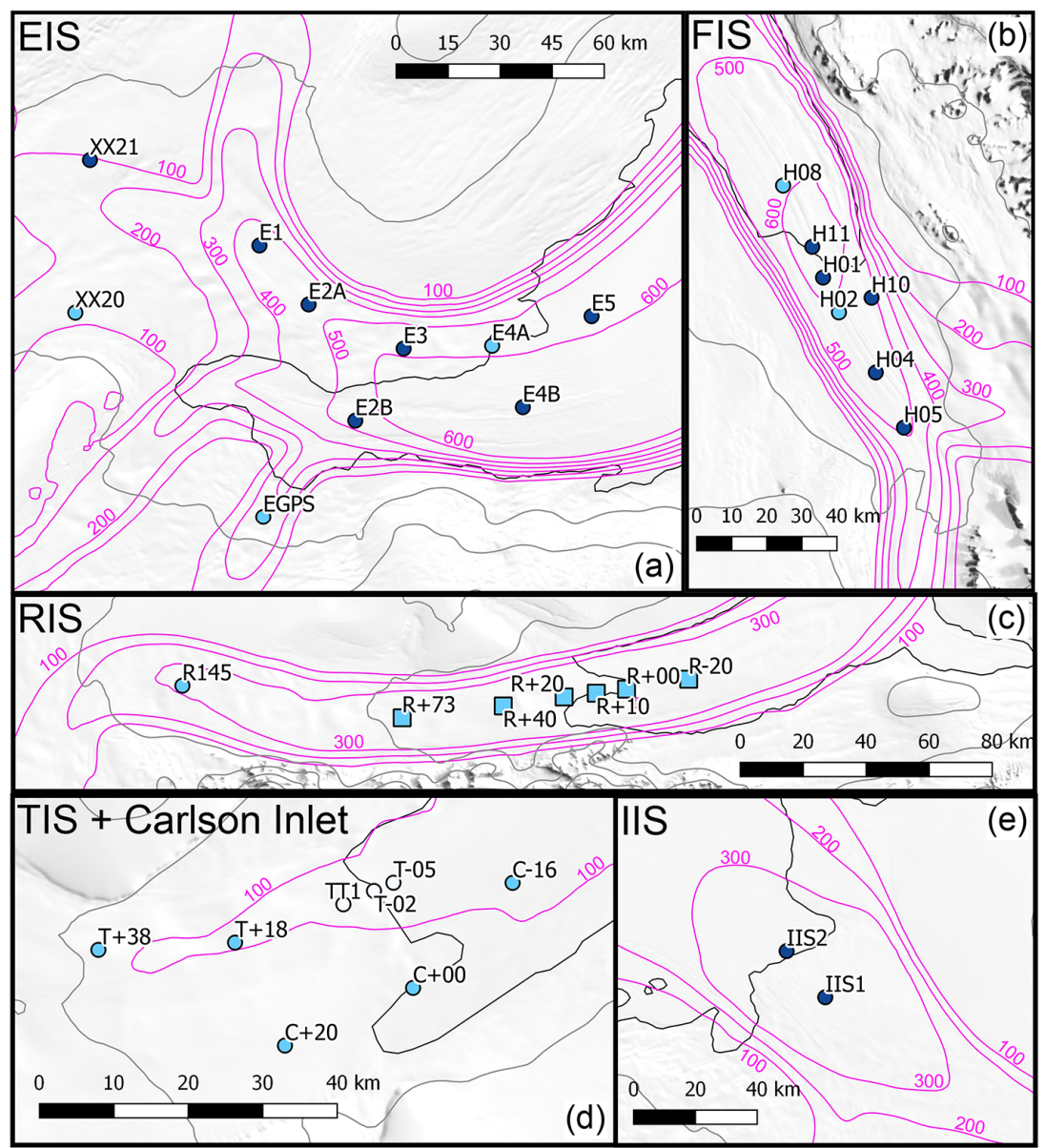

Figure 3. Close-up maps for each ice stream with relevant GPS data, including Evans Ice Stream (EIS, a), Foundation Ice Stream (FIS, b), Rutford Ice Stream (RIS, c), Talutis Ice Stream (TIS, d), and Institute Ice Stream (IIS, e). Magenta lines are velocity contours at 100 ma $^{-1}$ intervals, black lines are grounding lines, and grey lines are ice surface contours at $400 \mathrm{~m}$ intervals. Background shading is MOA satellite imagery (Haran et al., 2014). Scale bars are shown separately for each map.

in which each observation is weighted to minimize the influence of outliers. Remaining residuals in the tidal fit may include low-frequency and/or weather effects in addition to the noise resulting from measurement error. UTide makes use of the spectral properties of these underlying residuals and Monte Carlo uncertainty propagation to determine confidence intervals for the ellipse parameters (which are nonlinear functions of the least squares model parameters). The Rayleigh criterion (Pugh, 1996) was used by UTide to select which constituents were to be included in the analysis.

Each GPS record consists of three-dimensional positions, but we limit our discussion to the horizontal components of ice flow. We interpret the horizontal motion in terms of a tidal ellipse, which can be thought of as two polar vectors rotating in opposite directions such that when the vectors are aligned the speed is maximized and minimized when they oppose one another. If the two polar vectors have amplitudes $a^{+}$and $a^{-}$and phases $\epsilon^{+}$and $\epsilon^{-}$then the tidal ellipse can be conveniently characterized by four parameters:

$$
\begin{aligned}
& L_{q}^{\text {smaj }}=a_{q}^{+}+a_{q}^{-}, \\
& L_{q}^{\text {smin }}=a_{q}^{+}-a_{q}^{-}, \\
& \theta_{q}=\bmod \left[\frac{\epsilon_{q}^{+}+\epsilon_{q}^{-}}{2}, \pi\right],
\end{aligned}
$$

and

$\varphi_{q}=-\epsilon_{q}^{+}+\theta_{q}$,

where $L^{\text {smaj }}, L^{\text {smin }}, \theta$, and $\varphi$ are the semi-major and semiminor axis lengths, inclination, and Greenwich phase lag of the velocity vector respectively, and $q$ is the subscript for each constituent (Pugh, 1996). Figure 4 shows the ellipse parameters diagrammatically. For the sake of brevity, wherever we discuss the amplitude of tidal constituents in GPS displacement data, we mean specifically the length of the semimajor axis. In the case of the $M_{\mathrm{sf}}$ signal, which is the focus 


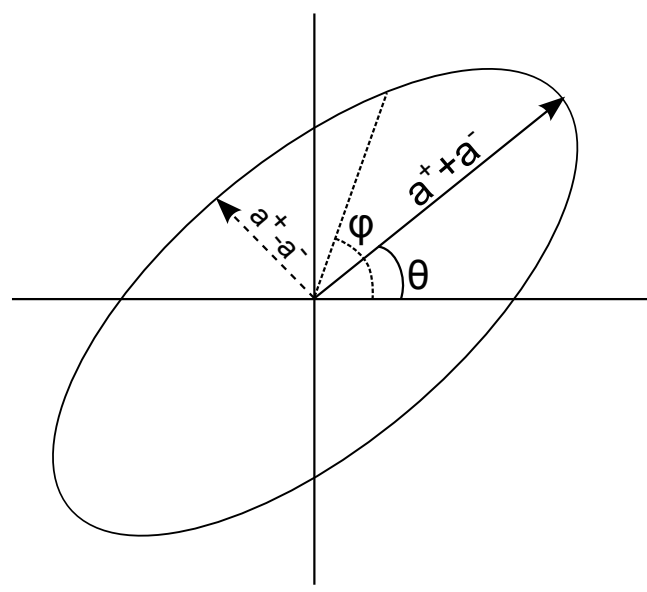

Figure 4. Tidal ellipse diagram, showing the four ellipse parameters: semi-major axis $\left(a^{+}+a^{-}\right)$, semi-minor axis $\left(a^{+}-a^{-}\right)$, inclination $(\theta)$, and Greenwich phase lag $(\varphi)$.

of our discussion, the semi-major axis always aligns closely with the mean flow and the length of the semi-minor axis is small in all cases. The $M_{2}$ constituent, on the other hand, has a much larger semi-minor axis on the main body of the ice shelf arising from the rotational character of the semidiurnal tide in this region, as described by Makinson et al. (2012).

\section{Results}

Fortnightly variations in ice flow are observed across the entire FRIS region and its adjoining ice streams (Fig. 5a). As in the case of the RIS, the signal penetrates far upstream of the GLs of all ice streams that were monitored with the exception of Carlson Inlet, which is stagnant (King, 2011). At the most upstream sites of RIS (145 km upstream) and EIS (132 km upstream) there is some indication of an $M_{\mathrm{sf}}$ signal but errors are too large to say this with any certainty (Fig. 5a). The $M_{\mathrm{sf}}$ signal is largest at the ice shelf calving front, and generally larger in faster flowing regions.

A long-period modulation in horizontal ice flow at the $S_{\mathrm{sa}}$ frequency is also observed across much of the FRIS (Fig. 5b). The $S_{\mathrm{sa}}$ response, first observed on RIS by Murray et al. (2007), could only be determined at a few sites where the record covered a sufficiently long time period. The exact required record length will depend on noise in the GPS data but in practice it must be at least as long as the period of the $S_{\text {sa }}$ constituent $(\sim 182$ days). Where detectable, it shows similar characteristics to the $M_{\text {sf }}$ signal, persisting upstream of GLs and with amplification towards the ice shelf calving front.

Amplitude of ice-shelf motion at the semidiurnal $M_{2}$ frequency is shown in Fig. 5c. As with the longer period signals, and as previously reported by Makinson et al. (2012), this semidiurnal component of horizontal ice motion is largest at the ice shelf calving front. Downstream of the RIS GL the low amplitude of $M_{2}$ is anomalous: all other ice streams show a larger $M_{2}$ component in this portion of the ice shelf (Fig. 6).

Vertical diurnal tides are small compared with semidiurnal tides across the whole region (Fig. 1b) and this is reflected in the horizontal amplitude of the $K_{1}$ constituent, which is small throughout the domain (Fig. 5d). Qualitatively, its distribution is very similar to that of the $M_{2}$ signal; being strongest at the calving front and near ice stream grounding lines.

To demonstrate the dominance of the $M_{\text {sf }}$ signal in the horizontal motion we show the predicted detrended displacements approximately $20 \mathrm{~km}$ upstream from the GL for each ice stream (Fig. 7). Also plotted is the vertical ocean tide (black line) on the ice shelf downstream of FIS. This site is chosen because, since the principle semidiurnal tides rotate in a clockwise direction around the FRIS, the vertical spring-neap cycle (and hence horizontal $M_{\mathrm{sf}}$ signal) will lead in phase at this point in our study region. Since GPS measurements were made over a number of years at different times the plot shows tidal prediction using UTide analysis of the sites, rather than actual data. Both RIS and EIS show the strongest $M_{\mathrm{sf}}$ signal upstream of the GL, but in all cases flow modulation at the $M_{\text {sf }}$ frequency dominates at these timescales.

In order to assess more clearly how the tidal signal propagates upstream of the major ice stream GLs, we plot alongflow transects of tidal parameters for FIS, RIS, TIS, and EIS in Fig. 6. Error bars are the $95 \%$ confidence intervals as calculated by UTide and described in the data analysis section. $M_{\text {sf }}$ flow modulation persists far upstream of RIS, FIS, and EIS but is almost undetectable $\sim 40 \mathrm{~km}$ upstream of TIS GL. $M_{\text {sf }}$ phase shows lag both upstream of GLs and east to west along the coastline. The semidiurnal $M_{2}$ constituent decays very rapidly upstream of the GLs, in agreement with previous observations, and is stronger on the ice shelf in all cases apart from the RIS. $M_{2}$ phase is not shown as values upstream of the GL at almost all sites are subject to very high uncertainties as a result of the very low $M_{2}$ amplitude.

\section{Discussion}

The pervasive nature of the $M_{\mathrm{sf}}$ signal in horizontal ice flow across the entire region clearly shows that this nonlinear effect, first observed on the RIS, is the norm rather than an oddity only generated under very particular conditions. The implication is that learning how to reproduce these effects in models will teach us much about general ice rheology and flow in Antarctica.

Recent analysis of high-resolution SAR satellite data on the RIS has suggested that the $M_{\mathrm{sf}}$ signal is larger on the floating portion of the ice stream than on the grounded ice (Minchew et al., 2016). The compilation of GPS data that we present here shows that this amplification on floating ice generally continues all the way to the ice shelf front (Fig. 5). While these observations do not invalidate nonlinear mecha- 

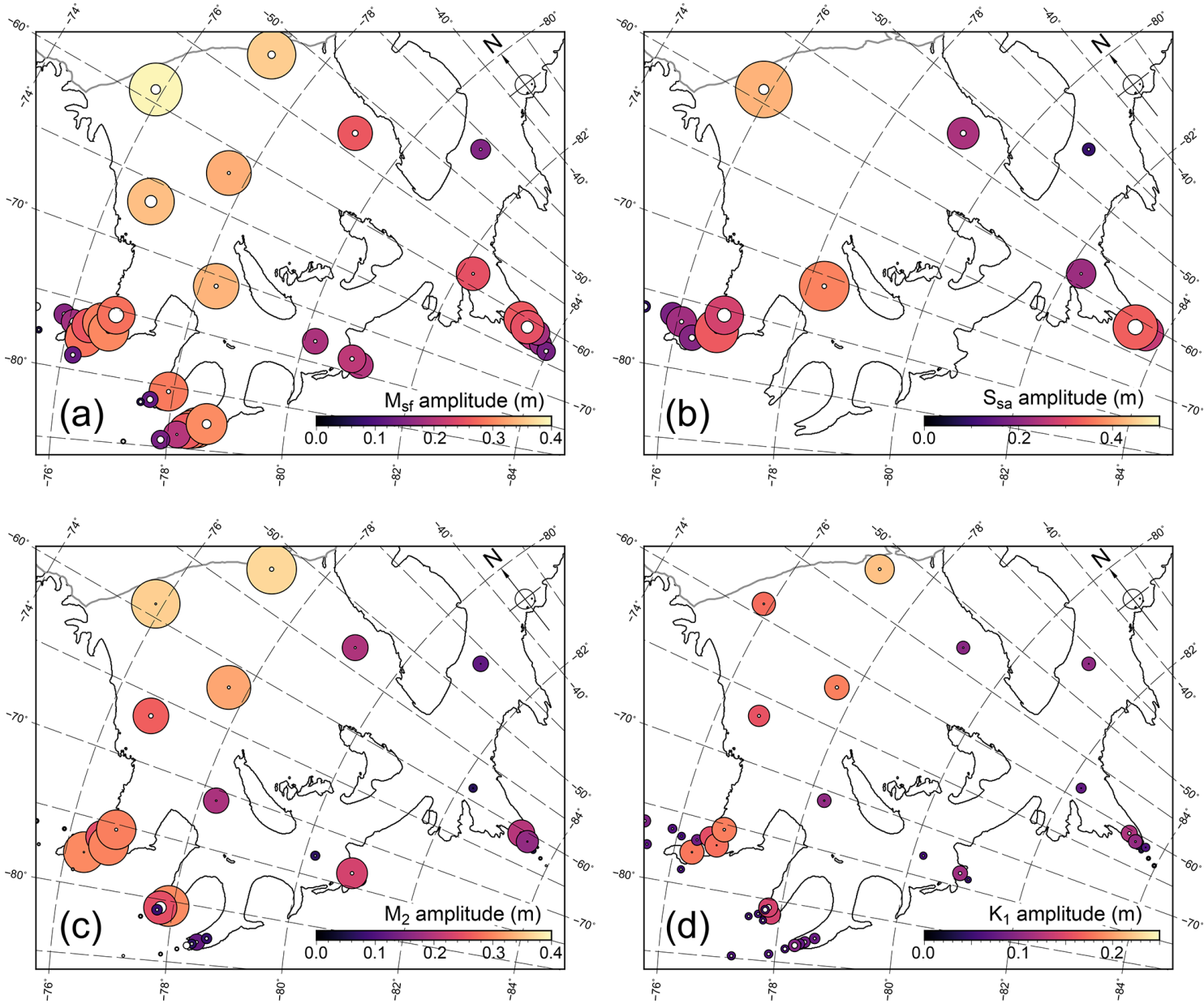

Figure 5. Tidal analysis of horizontal GPS displacements. Symbol area and colour show the semi-major axis amplitude. Error estimates for each component are overlain in white using the same scale. (Note that at most sites the errors are small compared to the amplitude and hence difficult to see.) Grounding lines are marked by black lines and the ice shelf front in grey.

nisms that generate the $M_{\mathrm{sf}}$ on grounded ice, they do suggest the need for a mechanism to generate fortnightly modulations in ice flow on floating ice. Minchew et al. (2016) proposed that widening of margins due to GL migration is one candidate that would produce an $M_{\mathrm{sf}}$ signal. While this may be the dominant mechanism in certain areas, such as the narrow embayment at the outlet of the RIS, it seems unlikely that this same mechanism is relevant over the entire FRIS where GL migration would only widen the ice shelf by a tiny fraction. Further modelling work is needed in order to explain the strength and spatial extent of the $M_{\mathrm{sf}}$ signal over the FRIS.

To better show the importance of the $M_{\mathrm{sf}}$ signal across the region, we interpolated amplitudes as measured by GPS from each site to cover the entire ice shelf and fast-flowing ice streams. The interpolation was done in MATLAB using the "v4" technique, which is based on the radial basis function method. The resulting map of $M_{\text {sf }}$ amplitudes (Fig. 8a) gives a general impression of how the $M_{\mathrm{sf}}$ signal increases towards the calving front and decays upstream of GLs. Note that in some regions of the ice shelf the interpolations are very poorly constrained and so should only be used as an indication of the spatial pattern of the $M_{\mathrm{sf}}$ signal (Fig. 5a).

The $M_{\text {sf }}$ signal modulates ice speed at a fortnightly period. We calculate the tidally varying ice velocity by taking the time derivative of the harmonic fit to the horizontal time series. In Fig. 8b we show the change in velocity due only to the $M_{\mathrm{sf}}$ flow modulation (which we call the $M_{\mathrm{sf}}$ velocity) as a percent of the mean ice speed. This reveals areas where estimates of ice velocity are most susceptible to aliasing issues arising from the $M_{\mathrm{sf}}$ signal. Although $M_{\mathrm{sf}}$ amplitude increases towards the ice front, the mean flow speed also increases and so the net result is a somewhat lower relative effect on mean flow. The largest percentages are seen where major ice streams un-ground and flow into the ice shelf, with the ice flow modulation of $\pm 15 \%$ over one fortnightly cycle.

In the same way that an interaction between the two principal semidiurnal constituents $\left(M_{2}\right.$ and $\left.S_{2}\right)$ leads to an $M_{\text {sf }}$ signal in ice flow, the two principal diurnal constituents $\left(K_{1}\right.$ 

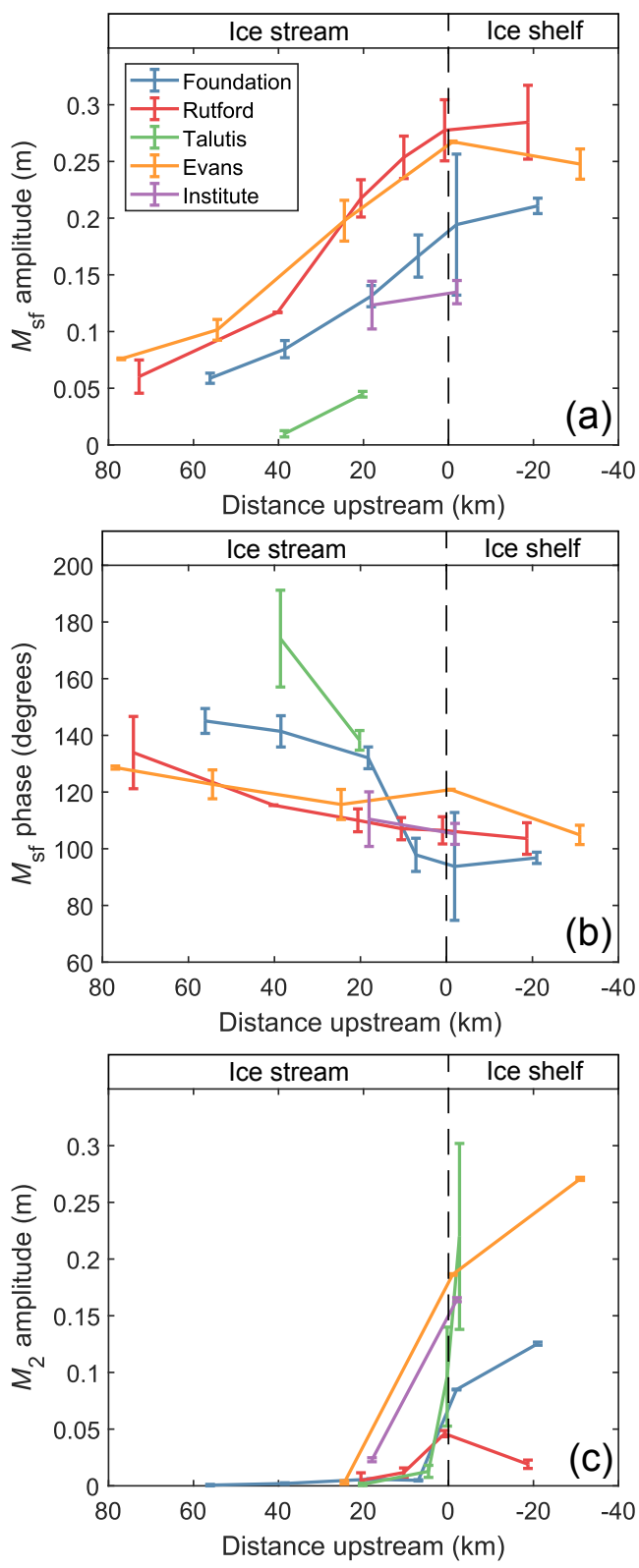

Figure 6. Along-flow transects across grounding lines of Foundation (blue lines), Rutford (red lines), Talutis (green lines), Evans (orange lines), and Institute (purple lines) ice streams showing $M_{\mathrm{sf}}$ amplitude (a), $M_{\text {sf }}$ phase (b), and $M_{2}$ amplitude (c) calculated from tidal analysis of horizontal ice displacements measured by GPS. Transects consist of sites H08, H11, H01, H10 on FIS; R-20, R+00, $\mathrm{R}+10, \mathrm{R}+20, \mathrm{R}+40, \mathrm{R}+73$ on RIS; $\mathrm{T}-05, \mathrm{~T}-02, \mathrm{TT} 1, \mathrm{~T}+18, \mathrm{~T}+38$ on TIS; E5, E4A, E3, E2A, E1 on EIS and IIS2, IIS1 on IIS. Error bars are the $95 \%$ confidence intervals as calculated by UTide and described in the data analysis section. Note that transects do not follow exact flow lines.

and $O_{1}$ ) will interact nonlinearly to produce an $M_{\mathrm{f}}$ response. This is somewhat difficult to separate from the $M_{\mathrm{sf}}$ signal because they have a similar periodicity (Table 1). Given that the semidiurnal constituents are generally much larger than the

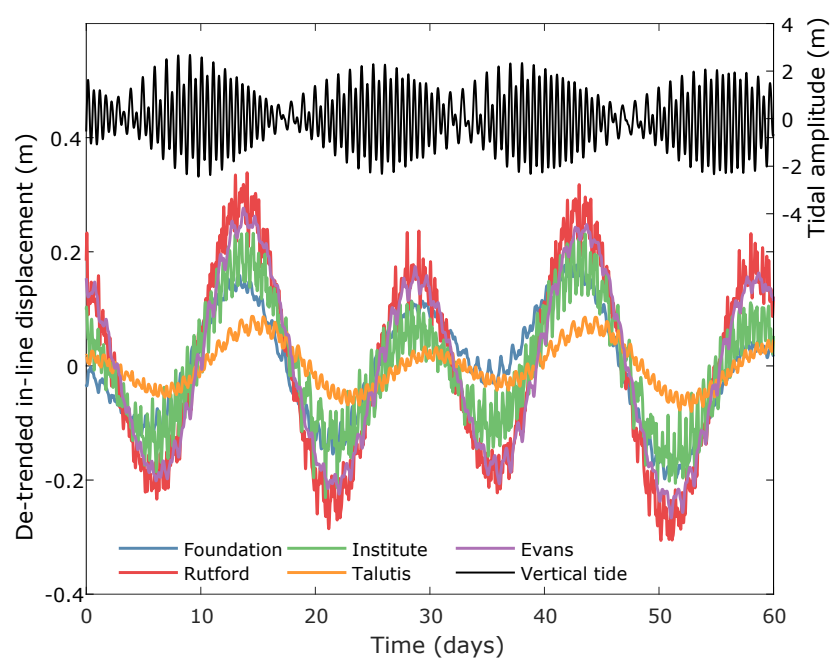

Figure 7. Horizontal de-trended displacements predicted for Foundation, Rutford, Talutis, and Evans ice streams based on GPS observations made approximately $20 \mathrm{~km}$ upstream in each case. Predicted vertical tidal motion on the freely floating outlet to FIS are also shown in black. Tidal reconstruction made using UTide software, including all tidal constituents with signal-to-noise ratio $(\mathrm{SNR})>2$.

diurnals beneath the FRIS we can be confident that the $M_{\mathrm{sf}}$ response is most important, but there is likely to be some response in ice flow at the $M_{\mathrm{f}}$ frequency (King et al., 2010). Indeed, at the GL of the Ross Ice Shelf where the principal diurnal constituents are much larger than the semidiurnals, a response at the $M_{\mathrm{f}}$ frequency is readily observed (Marsh et al., 2013).

A further effect of the nonlinearity that generates a fortnightly modulation in ice flow is that it can increase the mean ice speed (Gudmundsson, 2007, 2011; Rosier et al., 2014b). A nonlinear mechanism is needed to generate the $M_{\mathrm{sf}}$ signal, i.e. horizontal ice flow $(u)$ must have some nonlinear relationship to vertical ice-shelf displacements $(h)$. This can be expressed most simply as $u \propto h^{\alpha}$ where $\alpha \neq 1$. Regardless of the mechanism being invoked, if $\alpha>1$ the mean velocity will be increased, whereas a mechanism in which $\alpha<1$ would reduce the mean velocity. All current theories that explain the $M_{\text {sf }}$ signal on either ice shelves or ice streams find that $\alpha>1$. The large spatial extent of the $M_{\text {sf }}$ signal presented here implies that the flow of entire ice shelf is flowing faster than it would without this effect (or if the amplitude of the generating semidiurnal tides were to be reduced). Conversely, increased tidal amplitudes potentially caused by ice shelf retreat (Rosier et al., 2014a) could lead to a speed-up. Determining the amount by which the mean speed is affected as a result of the nonlinearity requires further modelling.

The amplitude of the $M_{\mathrm{sf}}$ signal at all sites shows some correlation with mean flow velocity $\left(R^{2}=0.653\right.$, Fig. A1). The contrast in $M_{\text {sf }}$ signal between Carlson Inlet and neighbouring TIS suggests that any valid mechanism for the generation of fortnightly flow modulation requires ice to be fast 

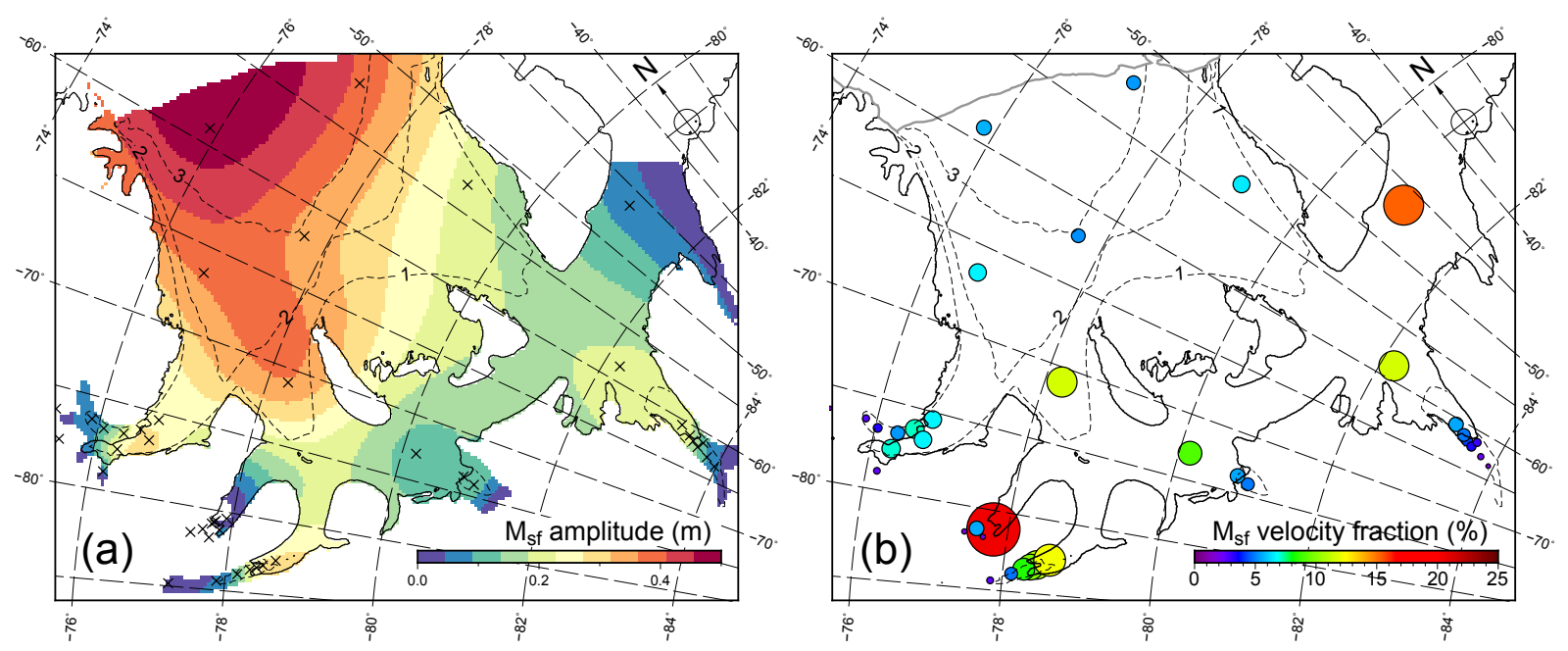

Figure 8. Interpolated amplitude of the $M_{\mathrm{sf}}$ signal (a) and $M_{\mathrm{sf}}$ velocity as a percentage of the mean speed (b, represented by symbol area and colour). The $M_{\text {sf }}$ amplitude in (a) is interpolated from observations (black crosses, values shown in Fig. 5a) using MATLAB "v4" interpolation. Grounding lines are marked by black lines and dashed grey lines are ice velocity contours at $1 \mathrm{~m} \mathrm{~d}^{-1}$ intervals.

flowing, and that no measurable $M_{\mathrm{sf}}$ signal will be present upstream of slow-moving ice such as the stagnant Carlson Inlet. $M_{\mathrm{sf}}$ phase velocity upstream of ice stream GLs is somewhat uniform, with two notable exceptions. On FIS there is a long phase lag between 7 and $18 \mathrm{~km}$ upstream of the GL which might be linked to a large over-deepening in this portion of the ice stream (Joughin et al., 2006); more sites are needed to study this behaviour in detail.

All sites with sufficiently long records measured a clear $S_{\text {sa }}$ tidal signal (Fig. 5b). The $S_{\text {sa }}$ frequency is a long-period constituent that simulates the change in declination of the sun, which itself modulates the strength of the principal solar tidal constituent $\left(S_{2}\right)$. As with the $M_{\text {sf }}$ signal, there is almost no measurable vertical $S_{\mathrm{sa}}$ tide beneath the FRIS (Table 1). Long-period modulation in horizontal ice flow at the $S_{\mathrm{sa}}$ frequency has been observed previously on the RIS (Murray et al., 2007) and Larsen Ice Shelf (King et al., 2011a) and likely arises from the same nonlinear mechanism that generates the $M_{\mathrm{sf}}$ signal (King et al., 2010). Because of the long period of this signal, the apparently large amplitude has little effect on ice velocity from equinox to solstice. As a result it does not present the same aliasing dangers as the $M_{\text {sf }}$ signal, which could affect satellite interferometric estimates of ice velocity (Gudmundsson, 2006).

\section{Data availability}

The new GPS data described herein are available through the UK Polar Data Centre in netCDF format (https://doi.org/10.5285/4fe11286-0e53-4a03-854ca79a44d1e356) (H. Gudmundsson et al., 2017).

\section{Conclusions}

The extensive data set of GPS records and the large tidal ranges make the FRIS an excellent place to investigate tidal effects on ice flow. We have presented GPS observations from across the FRIS and adjoining ice streams, showing clear tidal modulation of horizontal ice flow at almost all sites upstream of the GL to $\sim 80 \mathrm{~km}$ and downstream to the ice shelf front. This compilation of GPS data greatly expands on previous data sets, particularly for grounded ice. We also reanalysed previously released GPS results from the FilchnerRonne Ice Shelf to search for longer period tidal effects that were not originally included.

Observations of these tidal effects are used extensively to gain insights into ice rheology and flow. Of particular interest is the fortnightly modulation in ice flow, not present in the tidal forcing but driven by a nonlinear response to the ocean tides. Previously, observations of this effect were limited to a few locations around Antarctica. This signal is easily observable at almost every site presented with a sufficiently long record to resolve it. In addition to short-term variations in flow, this nonlinear effect is likely to result in higher mean ice velocity. With the $M_{\mathrm{sf}}$ signal now demonstrated to cover the entire ice shelf system, in some cases with a larger amplitude than originally observed on RIS, there are clear implications for the flow of the entire FRIS.

Many aspects of these observations are still poorly understood and this new data set shows their relevance to general ice dynamics. In particular, no proposed mechanism can adequately explain the amplification of fortnightly variations in ice flow towards the ice front which is readily observable in this data set. Further theoretical and modelling work is needed to better understand the processes that lead to the flow of ice being so sensitive to ocean tides. 
Appendix A: GPS stations

Table A1. Details of new GPS data presented in this study. New sites are in bold font. Total time is the time in days from first to last observation, whereas useful days is the number of days with at least $95 \%$ of data.

\begin{tabular}{|c|c|c|c|c|c|c|c|c|}
\hline Site name & Date first & Date last & $\begin{array}{r}\text { Total (useful) } \\
\text { days }\end{array}$ & $\begin{array}{r}\text { Latitude } \\
\left({ }^{\circ}\right)\end{array}$ & $\begin{array}{r}\text { Longitude } \\
\left({ }^{\circ}\right)\end{array}$ & $\begin{array}{r}\text { Mean velocity } \\
\left(\mathrm{m} \mathrm{d}^{-1}\right)\end{array}$ & $\begin{array}{r}M_{\text {sf }} \text { amplitude } \\
\text { (m) }\end{array}$ & $\begin{array}{r}M_{2} \text { amplitude } \\
(\mathrm{m})\end{array}$ \\
\hline $\mathrm{C}+00$ & 5-Dec-05 & 15-Dec-05 & $69(24)$ & -77.85 & -81.18 & 0.1 & 0.07 & 0.03 \\
\hline $\mathrm{C}+20$ & 6-Dec-05 & 9-Feb-06 & $65(65)$ & -77.72 & -81.75 & 0.06 & 0 & $\mathbf{0}$ \\
\hline C-16 & 1-Feb-06 & 12-Feb-06 & 69 (17) & -77.92 & -80.41 & 0.37 & 0.26 & 0.29 \\
\hline E1 & 26-Jan-09 & 12-Feb-09 & 284 (182) & -75.89 & -76.27 & 1.19 & 0.08 & $\mathbf{0}$ \\
\hline E2A & 19-Sep-09 & 6-Jan-10 & $345(188)$ & -76.07 & -76.63 & 1.27 & 0.1 & $\mathbf{0}$ \\
\hline E2B & 26-Jan-09 & 7-Мау-09 & 347 (177) & -76.31 & -77.58 & 1.52 & 0.25 & 0.29 \\
\hline E3 & 28-Jan-09 & 15-May-09 & $107(106)$ & -76.35 & -76.64 & 1.58 & 0.2 & $\mathbf{0}$ \\
\hline E4A & 28-Jan-09 & 9-Mar-09 & $41(41)$ & -76.56 & -76.2 & 1.58 & 0.27 & 0.19 \\
\hline E4B & 28-Jan-09 & 22-Apr-09 & $343(170)$ & -76.7 & -76.68 & 1.84 & 0.28 & 0.28 \\
\hline E5 & 9-Feb-09 & 18-Jul-09 & 339 (282) & -76.76 & -75.41 & 1.57 & 0.25 & 0.27 \\
\hline EGPS & 5-Dec-05 & 19-Jan-06 & $46(46)$ & -76.19 & -78.95 & 0.77 & 0.05 & $\mathbf{0}$ \\
\hline FR02 & 17-Dec-07 & 12-Apr-08 & $378(212)$ & -80.99 & -46.29 & 0.19 & 0.07 & 0.04 \\
\hline FR03 & 29-Jan-08 & 6-Apr-08 & $223(76)$ & -82.21 & -58.55 & 0.72 & 0.2 & 0.01 \\
\hline FR04 & 2-Dec-08 & 10-Jan-09 & $39(39)$ & -80.18 & -72.88 & 0.53 & 0.11 & 0.01 \\
\hline FR05 & 6-Dec-07 & 9-Dec-08 & 370 (344) & -78.26 & -70.9 & 1.32 & 0.36 & 0.11 \\
\hline FR06 & 6-Dec-07 & 30-Jan-08 & $55(55)$ & -76.69 & -66.51 & 2.38 & 0.38 & 0.22 \\
\hline FR07 & 9-Dec-07 & 4-Jul-08 & 407 (320) & -75.88 & -59.13 & 3.62 & 0.48 & 0.41 \\
\hline FR08 & 3-Dec-07 & 21-Dec-07 & $18(18)$ & -77.68 & -61.9 & 2.82 & 0.35 & 0.33 \\
\hline FR09 & 2-Dec-07 & 5-Oct-08 & $391(358)$ & -79.15 & -53.19 & 1.35 & 0.21 & 0.12 \\
\hline FR10 & 2-Dec-07 & 18-Feb-08 & $78(78)$ & -77.19 & -52.2 & 3.15 & 0.4 & 0.43 \\
\hline H01 & 28-Dec-15 & 27-Apr-16 & $362(206)$ & -83.56 & -61.58 & 1.67 & 0.16 & 0.01 \\
\hline H02 & 2-Jan-16 & 20-Mar-16 & 79 (79) & -83.65 & -61.98 & 1.6 & 0.13 & 0.01 \\
\hline H04 & 2-Jan-16 & 5-Mar-16 & $64(64)$ & -83.83 & -62.55 & 1.52 & 0.08 & $\mathbf{0}$ \\
\hline H05 & 2-Jan-16 & 1-Mar-16 & $60(60)$ & -83.97 & -63.19 & 1.41 & 0.06 & $\mathbf{0}$ \\
\hline H08 & 10-Jan-16 & 17-Apr-16 & $97(97)$ & -83.33 & -60.55 & 1.61 & 0.21 & 0.13 \\
\hline H10 & 10-Jan-16 & 7-Apr-16 & 348 (165) & -83.69 & -61.22 & 1.48 & 0.1 & $\mathbf{0}$ \\
\hline H11 & 1-Oct-16 & 23-Dec-16 & $361(120)$ & -83.49 & -61.19 & 1.69 & 0.19 & 0.09 \\
\hline IIS1 & 29-Jan-13 & 22-Jul-13 & 175 (175) & -81.04 & -73.98 & 1.06 & 0.12 & 0.03 \\
\hline IIS2 & 18-Jan-14 & 20-May-14 & $123(121)$ & -80.88 & -73.54 & 1.03 & 0.13 & 0.16 \\
\hline$R+00$ & 22-Dec-03 & 15-Feb-04 & $56(56)$ & -78.49 & -83.09 & 1.08 & 0.28 & 0.05 \\
\hline$R+10$ & 22-Dec-03 & 13-Feb-04 & $54(54)$ & -78.41 & -83.28 & 1.09 & 0.25 & 0.01 \\
\hline $\mathrm{R}+20$ & 21-Dec-03 & 13-Feb-04 & $54(54)$ & -78.32 & -83.47 & 1.1 & 0.21 & 0 \\
\hline $\mathrm{R}+40$ & 18-Dec-03 & 25-Jan-04 & 39 (39) & -78.16 & -83.85 & 1.02 & 0.12 & 0 \\
\hline $\mathrm{R}+73$ & 5-Dec-05 & 13-Feb-06 & $71(71)$ & -77.89 & -84.41 & 0.99 & 0.06 & 0 \\
\hline R-20 & 23-Dec-03 & 15-Feb-04 & $55(55)$ & -78.65 & -82.67 & 0.99 & 0.29 & 0.02 \\
\hline R145 & 5-Dec-05 & 15-Feb-06 & $73(73)$ & -77.25 & -84.83 & 0.8 & $\mathbf{0}$ & $\mathbf{0}$ \\
\hline$T+18$ & 6-Dec-05 & 7-Feb-06 & $63(63)$ & -77.62 & -81.28 & 0.34 & 0.04 & $\mathbf{0}$ \\
\hline $\mathbf{T}+38$ & 6-Dec-05 & 9-Feb-06 & $65(65)$ & -77.47 & -81.58 & 0.21 & 0.01 & $\mathbf{0}$ \\
\hline T-02 & 1-Feb-06 & 13-Feb-06 & $11(11)$ & -77.76 & -80.73 & 0.36 & $\mathbf{0}$ & 0.08 \\
\hline T-05 & 1-Feb-06 & 9-Feb-06 & $10(10)$ & -77.78 & -80.65 & 0.33 & 0 & 0.19 \\
\hline TT1 & 5-Feb-06 & 12-Feb-06 & 7 (7) & -77.73 & -80.87 & 0.34 & $\mathbf{0}$ & 0.02 \\
\hline XX20 & 8-Jan-10 & 10-Apr-10 & $92(92)$ & -75.53 & -77.71 & 0.34 & 0.01 & $\mathbf{0}$ \\
\hline XX21 & 5-Feb-10 & 22-Apr-10 & 356 (177) & -75.4 & -76.2 & 0.31 & 0.01 & $\mathbf{0}$ \\
\hline
\end{tabular}




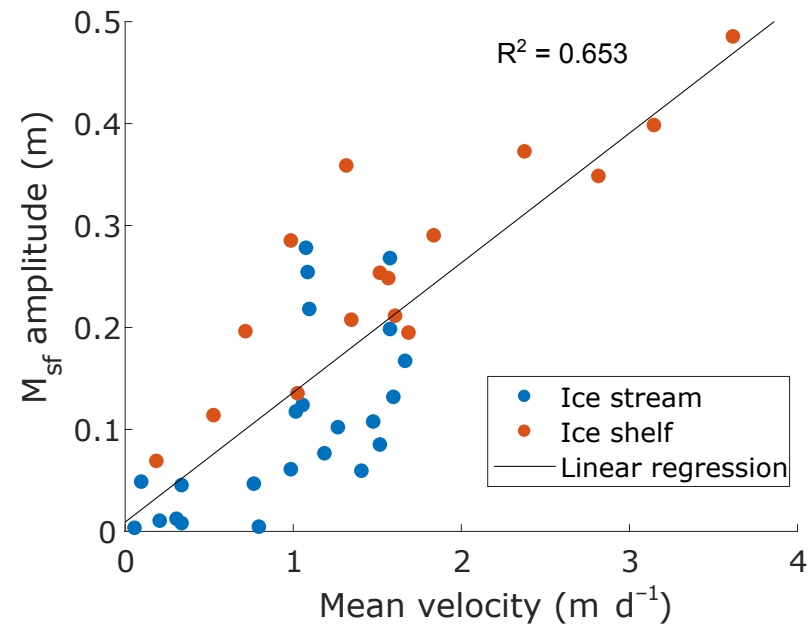

Figure A1. Relationship between mean velocity and $M_{\text {sf }}$ amplitude for GPS sites on ice streams (blue circles) and ice shelves (red circles), along with a linear regression (black line) giving an $R^{2}$ value of 0.653 . $R^{2}$ values for just ice streams or just ice shelves are 0.397 and 0.766 , respectively. The few sites with no measurable $M_{\mathrm{sf}}$ amplitude are not included. 
Competing interests. The authors declare that they have no conflict of interest.

Acknowledgements. Sebastian H. R. Rosier was funded by the UK Natural Environment Research Council large grant "Ice shelves in a warming world: Filchner Ice Shelf System" (NE/L013770/1). The work was also partly supported by a NERC Geophysical Equipment Facility loan (NERC grant NE/D009960/1), an Australian Research Council Future Fellowship (project number FT110100207) and the Australian Research Council Special Research Initiative for Antarctic Gateway Partnership (project ID SR140300001). We are very grateful to BAS logistics, pilots, and field assistants for their tireless work to help acquire the data and we are grateful to Brent Minchew for his help in producing some of the figures. We also thank the reviewers (Laurie Padman and Ryan Walker) and editor (Reinhard Drews) for their helpful comments on the paper.

Edited by: Reinhard Drews

Reviewed by: Laurence Padman and Ryan Walker

\section{References}

Anandakrishnan, S. and Alley, R.: Tidal forcing of basal seismicity of ice stream C, West Antarctica, observed far inland, J. Geophys. Res., 102, 15813-15196, https://doi.org/10.1029/97JB01073, 1997.

Anandakrishnan, S., Voigt, D. E., and Alley, R. B.: Ice stream D flow speed is strongly modulated by the tide beneath the Ross Ice Shelf, Geophys. Res. Lett., 30, 1361, https://doi.org/10.1029/2002GL016329, 2003.

Bindschadler, R. A., King, M. A., Alley, R. B., Anandakrishnan, S., and Padman, L.: Tidally controlled stick-slip discharge of a West Antasrctic ice stream, Science, 301, 1087-1089, https://doi.org/10.1126/science.1087231, 2003a.

Bindschadler, R. A., Vornberger, P. L., King, M. A., and Padman, L.: Tidally driven stickslip motion in the mouth of Whillans Ice Stream, Antarctica, Ann. Glaciol., 36, 263-272, https://doi.org/10.3189/172756403781816284, 2003b.

Brunt, K. M. and MacAyeal, D. R.: Tidal modulation of ice-shelf flow: a viscous model of the Ross Ice Shelf, J. Glaciol., 60, 500508, https://doi.org/10.3189/2014JoG13J203, 2014.

Brunt, K. M., King, M. A., Fricker, H. A., and Macayeal, D. R.: Flow of the Ross Ice Shelf, Antarctica, is modulated by the ocean tide, J. Glaciol., 56, 2005-2009, 2010.

Codiga, D. L.: Unified Tidal Analysis and Prediction Using the UTide Matlab Functions, Tech. rep., Graduate School of Oceanography, University of Rhode Island, Narragansett, RI, 2011

Dach, R., Beutler, G., and Gudmundsson, G.: Analysis of GPS Data from An Antarctic Ice Stream, Springer Berlin Heidelberg, Berlin, Heidelberg, 569-579, https://doi.org/10.1007/978-3-54085426-5_67, 2009.

Doake, C., Corr, H. F. J., Nicholls, K. W., Gaffikin, A., Jenkins, A., Bertiger, W. I., and King, M. A.: Tide-induced lateral movement of Brunt Ice Shelf, Antarctica, Geophys. Res. Lett., 29, 67-1-674, https://doi.org/10.1029/2001GL014606, 2002.
Gudmundsson, G. H.: Fortnightly variations in the flow velocity of Rutford Ice Stream, West Antarctica, Nature, 444, 1063-1064, https://doi.org/10.1038/nature05430, 2006.

Gudmundsson, G. H.: Tides and the flow of Rutford Ice Stream, West Antarctica, J. Geophys. Res., 112, F04007, https://doi.org/10.1029/2006JF000731, 2007.

Gudmundsson, G. H.: Ice-stream response to ocean tides and the form of the basal sliding law, The Cryosphere, 5, 259-270, https://doi.org/10.5194/tc-5-259-2011, 2011.

Gudmundsson, G. H., De Rydt, J., and Nagler, T.: Five decades of strong temporal variability in the flow of Brunt Ice Shelf, Antarctica, J. Glaciol., 63, 164-175, https://doi.org/10.1017/jog.2016.132, 2017.

Gudmundsson, H., Fenney, N., and Rosier, S. H. R.: Timeseries from GPS units deployed on ice streams and the adjoining ice shelf across the Filchner-Ronne region, Antarctica, 2005-2016, Polar Data Centre, Natural Environment Research Council, UK, https://doi.org/10.5285/4fe11286-0e534a03-854c-a79a44d1e356, 2017.

Haran, T., Bohlander, J., Scambos, T., Painter, T., and Fahnestock, M.: MODIS Mosaic of Antarctica 2008-2009 (MOA2009) Image Map, Version 1.1, https://doi.org/10.7265/N5KP8037, 2014.

Joughin, I., Bamber, J. L., Scambos, T., Tulaczyk, S., Fahnestock, M., and MacAyeal, D. R.: Integrating satellite observations with modelling: basal shear stress of the Filcher-Ronne ice streams, Antarctica, Philos. T. Roy. Soc. A, 364, 1795-1814, https://doi.org/10.1098/rsta.2006.1799, 2006.

King, E. C.: Ice stream or not? Radio-echo sounding of Carlson Inlet, West Antarctica, The Cryosphere, 5, 907-916, https://doi.org/10.5194/tc-5-907-2011, 2011.

King, M. A., Murray, T., and Smith, A. M.: Non-linear responses of Rutford Ice Stream, Antarctica, to semidiurnal and diurnal tidal forcing, J. Glaciol., 56, 167-176, https://doi.org/10.3189/002214310791190848, 2010.

King, M. A., Makinson, K., and Gudmundsson, G. H.: Nonlinear interaction between ocean tides and the Larsen C Ice Shelf system, Geophys. Res. Lett., 38, L08501, https://doi.org/10.1029/2011GL046680, 2011a.

King, M. A., Padman, L., Nicholls, K., Clarke, P. J., Gudmundsson, G. H., Kulessa, B., and Shepherd, A.: Ocean tides in the Weddell Sea: New observations on the Filchner-Ronne and Larsen $\mathrm{C}$ ice shelves and model validation, J. Geophys. Res., 116, C06006, https://doi.org/10.1029/2011JC006949, 2011b.

Legresy, B., Wendt, A., Tabacco, I., Remy, F., and Dietrich, R.: Influence of tides and tidal current on Mertz Glacier, Antarctica, J. Glaciol., 50, 427-435, https://doi.org/10.3189/172756504781829828, 2004.

Makinson, K., King, M. A., Nicholls, K. W., and Gudmundsson, G. H.: Diurnal and semidiurnal tide-induced lateral movement of Ronne Ice Shelf, Antarctica, Geophys. Res. Lett., 39, L10501, https://doi.org/10.1029/2012GL051636, 2012.

Marsh, O. J., Rack, W., Floricioiu, D., Golledge, N. R., and Lawson, W.: Tidally induced velocity variations of the Beardmore Glacier, Antarctica, and their representation in satellite measurements of ice velocity, The Cryosphere, 7, 1375-1384, https://doi.org/10.5194/tc-7-1375-2013, 2013.

Minchew, B. M., Simons, M., Riel, B., and Milillo, P.: Tidally induced variations in vertical and horizontal motion on Rutford Ice Stream, West Antarctica, inferred from remotely 
sensed observations, J. Geophys. Res.-Earth, 122, 167-190, https://doi.org/10.1002/2016JF003971, 2016.

Murray, T., Smith, A., King, M. A., and Weedon, G. P.: Ice flow modulated by tides at up to annual periods at Rutford Ice Stream, West Antarctica, Geophys. Res. Lett., 34, L18503, https://doi.org/10.1029/2007GL031207, 2007.

Padman, L., Fricker, H. A., Coleman, R., Howard, S., and Erofeeva, S. Y.: A new tide model for the Antarctic ice shelves and seas, Ann. Glaciol., 34, 247-254, 2002.

Pugh, D. T.: Tides, surges and mean sea level, John Wiley and Sons Ltd., Chippenham, Wiltshire, 1996.

Rignot, E., Mouginot, J., and Scheuchl, B.: Ice flow of the Antarctic Ice Sheet, Science, 333, 1427-1430, https://doi.org/10.1126/science.1208336, 2011.

Robel, A. A., Tsai, V. C., Minchew, B., and Simons, M.: Tidal modulation of ice shelf buttressing stresses, Ann. Glaciol., 1-9, https://doi.org/10.1017/aog.2017.22, 2017.

Rosier, S. H. R., Green, J. A. M., Scourse, J. D., and Winkelmann, R.: Modeling Antarctic tides in response to ice shelf thinning and retreat, J. Geophys. Res.-Oceans, 119, 87-97, https://doi.org/10.1002/2013JC009240, 2014a.

Rosier, S. H. R., Gudmundsson, G. H., and Green, J. A. M.: Insights into ice stream dynamics through modelling their response to tidal forcing, The Cryosphere, 8, 1763-1775, https://doi.org/10.5194/tc-8-1763-2014, 2014b.

Rosier, S. H. R., Gudmundsson, G. H., and Green, J. A. M.: Temporal variations in the flow of a large Antarctic ice stream controlled by tidally induced changes in the subglacial water system, The Cryosphere, 9, 1649-1661, https://doi.org/10.5194/tc9-1649-2015, 2015.
Sergienko, O. V., Macayeal, D. R., and Bindschadler, R. A.: Stick-slip behavior of ice streams: modeling investigations, Ann. Glaciol., 50, 87-94, https://doi.org/10.3189/172756409789624274, 2009.

Thompson, J., Simons, M., and Tsai, V. C.: Modeling the elastic transmission of tidal stresses to great distances inland in channelized ice streams, The Cryosphere, 8, 2007-2029, https://doi.org/10.5194/tc-8-2007-2014, 2014.

Walker, R. T., Parizek, B. R., Alley, R. B., and Nowicki, S. M. J.: A Viscoelastic Model of Ice Stream Flow with Application to Stick-Slip Motion, Front. Earth Sci., 4, 2, https://doi.org/10.3389/feart.2016.00002, 2016.

Winberry, J. P., Anandakrishnan, S., Alley, R. B., Bindschadler, R. A., and King, M. A.: Basal mechanics of ice streams: Insights from the stick-slip motion of Whillans Ice Stream, West Antarctica, J. Geophys. Res., 114, F01016, https://doi.org/10.1029/2008JF001035, 2009.

Winberry, J. P., Anandakrishnan, S., Wiens, D. A., Alley, R. B., and Christianson, K.: Dynamics of stick-slip motion, Whillans Ice Stream, Antarctica, Earth Planet. Sc. Lett., 305, 283-289, https://doi.org/10.1016/j.epsl.2011.02.052, 2011.

Winberry, J. P., Anandakrishnan, S., Alley, R. B., Wiens, D. A., and Pratt, M. J.: Tidal pacing, skipped slips and the slowdown of Whillans Ice Stream, Antarctica, J. Glaciol., 60, 795-807, https://doi.org/10.3189/2014JoG14J038, 2014. 